\title{
An analysis of the influence of infection on overall survival rates, following modified posterior pelvic exenteration for advanced ovarian cancer
}

\author{
Maria Szymankiewicz ${ }^{1}$, Konrad Dziobek ${ }^{2}$, Marta Sznajdrowska ${ }^{3}$, \\ Lukasz Wicherek ${ }^{2,4}$, Magdalena Dutsch-Wicherek ${ }^{3}$ \\ ${ }^{1}$ Department of Microbiology, Professor Franciszek Lukaszczyk Oncology Center, Bydgoszcz, Poland \\ ${ }^{2}$ Clinical Department of Gynecological Oncology, Professor Franciszek Lukaszczyk Oncology Center, Bydgoszcz, Poland \\ ${ }^{3}$ Department of Chemotherapy, Professor Franciszek Lukaszczyk Oncology Center, Bydgoszcz, Poland \\ ${ }^{4}$ Department of Oncology, Radiotherapy and Oncological Gynecology, Ludwik Rydygier Collegium Medicum, \\ Nicolaus Copernicus University, Bydgoszcz, Poland
}

\begin{abstract}
Objectives: The aim of our study was to determine the association between the appearance of infection after modified posterior pelvic exenteration (MPE) and the time to adjuvant chemotherapy (TTC), and to examine whether infection has any impact on clinical results by delaying the start of chemotherapy.

Material and methods: Our retrospective study analyzed 77 patients who had undergone MPE followed by adjuvant chemotherapy. Postoperatively, either there was no residual tumor or, the residual tumor was less than $2.5 \mathrm{~mm}$, in $76.7 \%$ of the study patients. Our study group was divided into two subgroups for comparison; the first group consisted of 41 patients with postoperative infections, and the second group of 36 patients had no infections. The infections of the first group were monitored during a 90-day postoperative period. Median TTC and overall survival rates (OS) were determined for those patients who developed an infection as well as for those who did not.

Results: The expected 5-year survival rate was $0.40(S D=0.09)$ for those patients without infection and $0.17(S D=0.07)$ for those patients with infection. The survival curves of patients with infection and those without infection were significantly different statistically $(p=0.038)$. The median TTC differed significantly for those patients who developed infection compared with those patients who did not develop infection (37 days compared with 27.5 days respectively, $p=0.024$ ); and patients without infection were statistically more likely to receive chemotherapy within 25 days following surgery than in the subsequent 25-42-day period compared with those patients who did develop infection $(p=0.048)$. No statistically significant differences were found between the two groups in relation to results following the initiation of chemotherapy during the first 42 days postoperatively $(p=0.445)$.

Conclusions: The absence of postoperative infection was associated with better survival rates. Patients with infection experienced a longer time interval between surgery and the start of chemotherapy, without negative impact to their overall survival rates.
\end{abstract}

Key words: advanced ovarian cancer; overall survival; perioperative infections; time to chemotherapy

Ginekologia Polska 2018; 89, 11: 618-626

\section{INTRODUCTION}

The prognosis for women with advanced stage (III-IV) ovarian cancer depends mainly on the completeness of the cytoreductive procedure and, it is presumed, on the time interval that elapses between surgery and the start of adjuvant chemotherapy (TTC). The standard first-line treatment following cytoreduction, is the administration of a combination of paclitaxel and carboplatin [1]. According to the recommendation of the European Society for Medical Oncology (ESMO), patients who meet the eligibility criteria 
for receiving a human monoclonal antibody may receive standard chemotherapy in combination with bevacizumab [2-5]. The optimal time to chemotherapy remains unclear and opinions vary according to the clinical studies available; and this variety is largely due to the heterogeneous nature of the patient group under study. However, there is evidence that associates a time delay in administrating chemotherapy with decreased survival rates $[6,7]$. The study by Wright et al. [8] reported that a TTC of 6 weeks or less did not influence OS (overall survival rates). However, the review article by Alexander et al. [9], recommends starting chemotherapy within 4 weeks of surgery.

The extent of residual tumor tissue following surgery is directly related to patient survival outcomes [10-12]. For this reason, the aim of surgery is the removal of all neoplastic foci during the cytoreductive procedure, and the standard approach is to achieve no gross residual disease (NGR) [13]. In a meta-analysis, Du Bois et al. [14] reported that the removal of all foci results in a median overall survival period of more than 99 months, while leaving a residual tumor of less than $1 \mathrm{~cm}$ correlates with a median overall survival rate of less than 36 months. In the 1990s, Eisenkop [15] introduced modified posterior pelvic exenteration (MPE) to facilitate the removal of all visible tumor foci. When MPE is performed, cancer recurrence in the Pouch of Douglas is significantly less likely than following a more conservative surgical approach based on hysterectomy [16]. Nevertheless, such extensive cytoreductive surgery can be associated with increased postoperative morbidity and mortality, because various postoperative complications may occur, including infection [17-21]. Long-term, surgical procedures such as large bowel resection, are risk factors for different of a variety of types of infection that are frequently caused by microorganisms originating from the patient's own flora [22].

Although numerous reasons for delaying chemotherapy have been established [23-25], the influence of infection on treatment delays has not been evaluated in women with advanced-stage (III and IV) ovarian cancer following MPE.

\section{Objectives}

In our study, we assessed the potential relationships between the appearance of infection and a longer-than-intended time to chemotherapy in patients who underwent MPE for advanced ovarian cancer. We also analyzed the OS of patients with infection and those without infection in relation to selected variables.

\section{MATERIAL AND METHODS}

For our study we selected 77 patients who had undergone MPE from the group of women with advanced ovarian cancer who had had primary cytoreductive surgery (CRS) in the Lukaszczyk Oncological Center in Bydgoszcz between August 2011 and November 2015. The patients were diagnosed at stage III C or IV, according to the International Federation of Gynecology and Obstetrics (FIGO) staging system for ovarian cancer. Multiple bowel resections, which are part of the surgical procedure, are associated with a higher frequency of perioperative infections. Therefore, all patients received the following antimicrobial prophylaxis which was commenced before they underwent surgery: Cefamandole IV $2.0 \mathrm{~g} 8$ dosis, q $6 \mathrm{~h}$, Metronidazole IV $0.5 \mathrm{~g}$ 6 dosis, q $8 \mathrm{~h}$ and Gentamicin IV $1.5 \mathrm{mg} / \mathrm{kg}$, based on dosing weight (single dose) intraoperatively (if the duration of surgery was $>4 \mathrm{~h}$ ), and according to the recommendation of the Hospital Infection Control Committee. However, regardless of the perioperative antibiotic prophylaxis used, due to the existences of multiple risk factors, patients undergoing MPE often experience infections. Directly after surgery, any residual tumors were evaluated by the surgeon in accordance with the Sugarbaker protocol [26]. Postoperatively, the 77 MPE patients in our study were under the care of the Chemotherapy Outpatient Clinic in our center. The observation time was within the range of 17 to 2133 days. Table 1 shows the clinical demographics of the patients we analyzed. Both demographic and clinical data were collected retrospectively from medical records. Information about the extent of each patient's surgery and chemotherapy was derived from medical protocols and records. This information included: completeness of the surgery and TTC in the following intervals: $<25$ days, $>=25<=42$, $>42$ days (we have taken $<=42$ days as an optimal time). Other information, such as dose reductions, longer interval between cycles, types of chemotherapeutic agents, dosages, the number of cycles administered, and schedules, as well as resistance to platinum, was also included. A carboplatin/paclitaxel-containing chemotherapeutic regimen was used as a standard treatment; and where that was not used, the following treatments were used: cisplatin/cyclophosphamide, carboplatin/cyclophosphamide, cisplatin/taxol, and carboplatin/gemcitabine. Alternatively, sometimes a one-drug treatment, consisting of doxorubicin, taxol, carboplatin, gemcitabine, was applied. Four patients who met the eligibility criteria for receiving a human monoclonal antibody received the standard carboplatin and paclitaxel chemotherapy in combination with bevacizumab. If the cancer progressed within 6 months of the completion of therapy the tumor was defined as platinum-resistant [27]. Information about infections was derived from medical records, the Hospital Infection Control Committee, and the Microbiology Department. We analyzed the perioperative infectious complications that occurred within the first 90 days following surgery. Surgical site infections (SSI), deep surgical site infections, wound complications (superficial skin infection), organ/space infections, bloodstream infections (BSI), urinary 
Table 1. Clinical demographics of analyzed patients

\begin{tabular}{|c|c|c|c|c|}
\hline Variables & $\begin{array}{l}\text { All patients } \\
(\mathrm{N}=77)\end{array}$ & $\begin{array}{l}\text { Patients with } \\
\text { infection }(\mathrm{N}=41)\end{array}$ & $\begin{array}{l}\text { Patients without } \\
\text { infection }(\mathrm{N}=36)\end{array}$ & $\begin{array}{l}\text { P-value } \\
\text { Patients with } \\
\text { infection vs patients } \\
\text { without infection }\end{array}$ \\
\hline Age (years), median, range & $58(26-78)$ & $59(26-78)$ & $58(30-77)$ & 0.411 \\
\hline Pre-operative $\mathrm{CA}-125$ value $(\mathrm{U} / \mathrm{mL})$, median, range & $578.0(17-21000)$ & $570.0(17-21000)$ & $578.0(32-14385)$ & 0.971 \\
\hline Pre-operative albumin value $(\mathrm{g} / \mathrm{L})$, median, range & $41.0(31.9-49.2)$ & $40.6(32.0-49.2)$ & $41.5(31.9-48.8)$ & 0.254 \\
\hline Pre-operative hemoglobin value ( $\mathrm{g} / \mathrm{dL})$, median, range & $12.1(8.6-15.3)$ & $12.4(10-15,3)$ & $11.8(8.6-14.0)$ & 0.075 \\
\hline Presence of diabetes, $\mathrm{N}, \%$ & $3(3.9 \%)$ & $2(4.9 \%)$ & $1(2.8 \%)$ & 0.635 \\
\hline $\begin{array}{l}\text { ASA score, N, \% } \\
\text { I } \\
\text { II } \\
\text { III } \\
\text { IV } \\
\text { Undefined }\end{array}$ & $\begin{array}{l}3(3.9 \%) \\
33(42.9 \%) \\
38(49.4 \%) \\
2(2.6 \%) \\
1(1.3 \%)\end{array}$ & $\begin{array}{l}0(0.0 \%) \\
19(46.3 \%) \\
21(51.2 \%) \\
1(2.4 \%) \\
0(0.0 \%)\end{array}$ & $\begin{array}{l}3(8.3 \%) \\
14(38.9 \%) \\
17(47.2 \%) \\
1(2.8 \%) \\
1(2.8 \%)\end{array}$ & 1.000 \\
\hline BMI $(\mathrm{kg} / \mathrm{m} 2)$, median, range & $25(15-48)$ & $26(15-35)$ & $25(25-48)$ & 0.650 \\
\hline \multicolumn{5}{|l|}{ Surgical procedures } \\
\hline Large omentectomy & $61(79.2 \%)$ & $33(80.5 \%)$ & $28(77.8 \%)$ & 0.770 \\
\hline Total hysterectomy and bilateral salpingoophorectomy & $55(71.4 \%)$ & $30(73.2 \%)$ & $25(69.5 \%)$ & 0.476 \\
\hline Rectosigmoidectomy & $77(100.0 \%)$ & $41(100.0 \%)$ & $36(100.0 \%)$ & - \\
\hline Partial small bowel resection & $24(31.2 \%)$ & $13(31.7 \%)$ & $11(30.6 \%)$ & 0.913 \\
\hline Hemicolectomy, or a total colectomy & $27(35.1 \%)$ & $15(36.6 \%)$ & $12(33.3 \%)$ & 0.765 \\
\hline Pelvicperitonectomy & $77(100.0 \%)$ & $41(100.0 \%)$ & $36(100.0 \%)$ & - \\
\hline lleostomy & $18(23.4 \%)$ & $10(24.4 \%)$ & $8(22.2 \%)$ & 0.823 \\
\hline $\begin{array}{l}\text { Colostomy } \\
\text { Protective ostomy }\end{array}$ & $\begin{array}{l}14(18.2 \%) \\
7(9.1 \%)\end{array}$ & $\begin{array}{l}9(22.0 \%) \\
4(9,8 \%)\end{array}$ & $\begin{array}{l}5(13.9 \%) \\
3(8,3 \%)\end{array}$ & $\begin{array}{l}0.360 \\
0.828\end{array}$ \\
\hline Bowel anastomosis & $53(68.8 \%)$ & $27(65.9 \%)$ & $26(72.2 \%)$ & 0.547 \\
\hline Splenectomy & $28(36.4 \%)$ & $15(36.6 \%)$ & $13(36.1 \%)$ & 0.966 \\
\hline $\begin{array}{l}\text { Histologic type, N, \% } \\
\text { Serous tumors } \\
\text { Non-serous }\end{array}$ & $\begin{array}{l}51(66.2 \%) \\
26(33.8 \%)\end{array}$ & $\begin{array}{l}26(63.4 \%) \\
15(36.6 \%)\end{array}$ & $\begin{array}{l}25(69.4 \%) \\
11(30.6 \%)\end{array}$ & 0.577 \\
\hline $\begin{array}{l}\text { Histological grading, N, \% } \\
2 \\
3 \\
\text { Undefined }\end{array}$ & $\begin{array}{l}39(50.6 \%) \\
25(32.5 \%) \\
13(16.9 \%)\end{array}$ & $\begin{array}{l}21(51.2 \%) \\
12(29.3 \%) \\
8(19.5 \%)\end{array}$ & $\begin{array}{l}18(50.0 \%) \\
13(36.1 \%) \\
5(13.9 \%)\end{array}$ & 0.648 \\
\hline $\begin{array}{l}\text { Lymph node involvement, N, \% } \\
\text { N0 } \\
\text { N1 } \\
\text { Undefined }\end{array}$ & $\begin{array}{l}12(15.6 \%) \\
32(41.6 \%) \\
33(42.9 \%)\end{array}$ & $\begin{array}{l}5(12.20 \%) \\
21(51.2 \%) \\
15(36.6 \%)\end{array}$ & $\begin{array}{l}7(19.4 \%) \\
11(30.6 \%) \\
18(50.0 \%)\end{array}$ & 0.150 \\
\hline $\begin{array}{l}\text { Completeness of cytoreductive surgery, N, \% } \\
\text { CCR0 } \\
\text { CCR1 } \\
\text { CCR2 } \\
\text { CCR3 }\end{array}$ & $\begin{array}{l}35(45.5 \%) \\
24(31.2 \%) \\
16(20.8 \%) \\
2(2.6 \%)\end{array}$ & $\begin{array}{l}16(39.0 \%) \\
16(39.0 \%) \\
9(22.0 \%) \\
0(0.0 \%)\end{array}$ & $\begin{array}{l}19(52.8 \%) \\
8(22.2 \%) \\
7(19.4 \%) \\
2(5.6 \%)\end{array}$ & 0.177 \\
\hline Total operative time (min.), median, range & $312(126-612)$ & 348 (126-612) & 300 (138-606) & 0.183 \\
\hline Death within 30 days after surgery & $1(1.3 \%)$ & $0(0.0 \%)$ & $1(2.8 \%)$ & - \\
\hline Death within 6 months after surgery & $12(15.6 \%)$ & $9(22.0 \%)$ & $3(8.3 \%)$ & 0.887 \\
\hline
\end{tabular}

N0 - no regional lymph node metastasis; $\mathrm{N} 1$ - regional lymph node metastasis; CCRO — indicates no residual tumor; CCR1 — less than $2.5 \mathrm{~mm}$ of residual tumor; CCR2 - between $2.5 \mathrm{~mm}$ and $2.5 \mathrm{~cm}$ of residual tumor; CCR3 - more than $2.5 \mathrm{~cm}$ of residual tumor; ASA score - American Society of Anesthesiologists score; BMI - body mass index; CA-125 - cancer antigen 125

tract infections (UTI), and lower respiratory tract infections (LRTI), were registered and classified according to the cur- rent criteria of the Centers for Disease Control and Prevention (CDC). Information on all the patients who died after 
Table 2. Infectious complications within 90 days after modified posterior pelvic exenteration $(n=41)$

\begin{tabular}{|l|l|}
\hline Type of infection & Number of patients \\
\hline Surgical site infection & 26 \\
\hline Urinary tract infection & 4 \\
\hline Bloodstream infection & 3 \\
\hline Multiple infections & 3 \\
\hline Surgical site infection + Urinary tract infection & 1 \\
\hline Surgical site infection + Lower respiratory tract infection & 1 \\
\hline Surgical site infection + Bloodstream infection & 1 \\
\hline Surgical site infection + Urinary tract infection + Bloodstream infection & 1 \\
\hline Surgical site infection + Urinary tract infection + Bloodstream infection + Lower respiratory tract infection & 1 \\
\hline Lower respiratory tract infection + Urinary tract infection + Surgical site infection & 1 \\
\hline Total & 41 \\
\hline
\end{tabular}

Surgical site infection included wound, deep or organ/space infections

\begin{tabular}{|c|c|c|c|c|c|c|c|}
\hline Characteristics & $\begin{array}{l}\text { All patients } \\
(\mathrm{N}=77)\end{array}$ & $\%$ & $\begin{array}{l}\text { Patients } \\
\text { number } \\
\text { with infection } \\
(\mathrm{N}=41)\end{array}$ & $\%$ & $\begin{array}{l}\text { Patients } \\
\text { number } \\
\text { without } \\
\text { infection } \\
(\mathrm{N}=36)\end{array}$ & $\%$ & $\begin{array}{l}\text { P-value } \\
\text { patients with } \\
\text { infection } \\
\text { vs patients } \\
\text { without } \\
\text { infection }\end{array}$ \\
\hline $\begin{array}{l}\text { TTC (median) } \\
\text { (time to chemotherapy), range, days }\end{array}$ & $33(13-153)$ & - & $37(14-153)$ & - & $27.5(13-120)$ & - & 0.024 \\
\hline $\begin{array}{l}\text { TTC by intervals } \\
-<25 \text { days } \\
-\geq 25 \text { days } \leq 42 \text { days } \\
->42 \text { days } \\
- \text { unknown } \\
<25 \text { days } \text { vs } \geq 25 \text { days } \leq 42 \text { days } \\
<25 \text { days } \text { vs }>42 \text { days } \\
\geq 25 \text { days } \leq 42 \text { days vs }>42 \text { days } \\
\leq 42 \text { days } \text { v }>42 \text { days }\end{array}$ & $\begin{array}{l}21 \\
31 \\
23 \\
2\end{array}$ & $\begin{array}{l}27.3 \\
40.3 \\
29.9 \\
2.6\end{array}$ & $\begin{array}{l}7 \\
19 \\
13 \\
2\end{array}$ & $\begin{array}{l}17.1 \\
46.3 \\
31.7 \\
4.9\end{array}$ & $\begin{array}{l}14 \\
12 \\
10 \\
0\end{array}$ & $\begin{array}{l}38.9 \\
33.3 \\
27.8 \\
0.0\end{array}$ & $\begin{array}{l}0.048 \\
0.120 \\
0.724 \\
0.445\end{array}$ \\
\hline $\begin{array}{l}\text { Dose reduction, prolongation of time } \\
\text { between cycles (all cytostatics) } \\
\text { - yes } \\
\text { - no } \\
\text { - unknown }\end{array}$ & $\begin{array}{l}22 \\
52 \\
3\end{array}$ & $\begin{array}{l}28.6 \\
67.5 \\
3.9\end{array}$ & $\begin{array}{l}4 \\
25 \\
2\end{array}$ & $\begin{array}{l}34.1 \\
61.0 \\
4.9\end{array}$ & $\begin{array}{l}8 \\
27 \\
1\end{array}$ & $\begin{array}{l}22.2 \\
75.0 \\
2.8\end{array}$ & 0.355 \\
\hline $\begin{array}{l}\text { Resistance to platinum } \\
\text { - yes } \\
\text { - no } \\
\text { - unknown }\end{array}$ & $\begin{array}{l}23 \\
47 \\
7\end{array}$ & $\begin{array}{l}29.9 \\
61.0 \\
9.1\end{array}$ & $\begin{array}{l}13 \\
23 \\
5\end{array}$ & $\begin{array}{l}31.7 \\
56.1 \\
12.2\end{array}$ & $\begin{array}{l}10 \\
24 \\
2\end{array}$ & $\begin{array}{l}27.8 \\
66.7 \\
5.6\end{array}$ & 0.551 \\
\hline $\begin{array}{l}\text { Carboplatin/paclitaxel } \\
\text { chemotherapeutic regimen } \\
\text {-yes } \\
\text { - no }\end{array}$ & $\begin{array}{l}61 \\
16\end{array}$ & $\begin{array}{l}79.2 \\
20.8\end{array}$ & $\begin{array}{l}32 \\
9\end{array}$ & $\begin{array}{l}78.0 \\
22.0\end{array}$ & $\begin{array}{l}29 \\
7\end{array}$ & $\begin{array}{l}80.6 \\
19.4\end{array}$ & 0.787 \\
\hline
\end{tabular}

TTC - time to chemotherapy

CRS, was retrieved for analysis from the database of the Kujawsko-Pomorski regional office of the National Health System of Poland.

The patients in our study were divided into two subgroups: 41 patients with infections and 36 without. We compared patients who developed infections within 90 days of MPE with those who did not, across a range of variables in order to assess the homogeneity of the subgroups analyzed in the study, and to exclude the influence of other possible factors relating to the extent of the surgery that would affect the OS outcome. For each subgroup, we analyzed the time to chemotherapy with respect to their OS. We also 


\begin{tabular}{|c|c|c|c|c|c|c|}
\hline Completeness of CRS & $\begin{array}{l}\text { Number of } \\
\text { patients with } \\
\text { infections }\end{array}$ & $\begin{array}{l}\text { Median TTC } \\
\text { patients with } \\
\text { infection, range } \\
\text { [days] }\end{array}$ & $\begin{array}{l}\text { Median time to } \\
\text { infection, range } \\
\text { [days] }\end{array}$ & $\begin{array}{l}\text { Number of } \\
\text { patients without } \\
\text { infections }\end{array}$ & $\begin{array}{l}\text { Median TTC } \\
\text { patients } \\
\text { without } \\
\text { infection, range } \\
\text { [days] }\end{array}$ & $\begin{array}{l}\text { P-value } \\
\text { patients with } \\
\text { infection } \\
\text { vs patients } \\
\text { without } \\
\text { infection } \\
\text { (median TTC) }\end{array}$ \\
\hline CCRO & 16 & 38 (27-98) & $12(2-80)$ & 19 & $29(13-120)$ & \\
\hline CCR1 & 16 & $39(17-153)$ & $20(3-90)$ & 8 & $34(14-56)$ & \\
\hline CCR2 & 9 & $26.5(14-47)$ & $13(3-89)$ & 7 & $23(17-36)$ & \\
\hline $\begin{array}{l}\text { CCR3 } \\
\text { CCR0/CCR1 } \\
\text { CCR2/CCR3 }\end{array}$ & 0 & - & - & 2 & $28.5(16 ; 41)$ & $\begin{array}{l}0.896 \\
0.304\end{array}$ \\
\hline
\end{tabular}

CRS - completeness of cytoreductive surgery; CCR0 - indicates no residual tumor; CCR1 - less than $2.5 \mathrm{~mm}$ of residual tumor; CCR2 - between $2.5 \mathrm{~mm}$ and $2.5 \mathrm{~cm}$ of residual tumor; $\mathrm{CCR} 3$ - more than $2.5 \mathrm{~cm}$ of residual tumor; TTC - time to chemotherapy

divided patients into groups according to the completeness of CRS and analyzed the relationships between long-term outcomes, and both the occurrence of infection and the extent of residual tumor tissue.

The study proposal was approved by the Bioethics Committee of the Collegium Medicum Nicolaus Copernicus University in Bydgoszcz, No KB 80/2017.

Data analysis was performed using STATISTICA version 13.0. Characteristics were compared between groups with the Chi-square test and the Mann-Whitney $U$ test. The Kaplan-Meyer method was applied for calculating OS. The Log Rank test was used to compare the curves. The results were analyzed for the end points: death or information from the Kujawsko-Pomorski regional office of the National Health System of Poland that no death was reported. Differences were considered statistically significant at $p<0.05$. Parameters were also expressed as medians and ranges.

\section{RESULTS}

We identified, for analysis, 77 patients with a median age of 58 (with a range of $26-78$ years), who had received adjuvant chemotherapy following primary cytoreductive surgery (MPE). Forty-one patients (53.2\%) from the group developed infections after surgery. SSI was observed among 34 patients, of whom 25 developed wound infections, and 9 deep or organ/space infections, including intra-abdominal abscesses. UTI was confirmed in 10 patients. BSI and LRTI manifested in 6 and 3 patients, respectively. In 8 of the 41 patients who developed infections, we detected multiple infections in sites two, three, and four. The median time to the appearance of infections ranged from 12-20 days, depending on the completeness of the CRS procedure. Table 2 shows the infectious complications that we recorded according to infection type.

The median time to postoperative chemotherapy was 33 days (with a range of 13-153 days): 37 days in patients with infections (with a range of 14-153 days), and 27.5 days in patients without infection (with a range of 13-120 days) ( $p=0.024) .67 .6 \%$ of the patients received chemotherapy within the optimal time frame (i.e., within 6 weeks). Dose reduction or prolongation of the time between cycles was found in $28.6 \%$ of patients. The median number of chemotherapy cycles was 6 (with a range of 1-11). When we analyzed the results of patients both with and without infection, we found that approximately $63 \%$ of patients with infection received chemotherapy within 6 weeks of surgery compared with $72.0 \%$ of those without infection $(p=0.445) .34 \%$ of those women with infections received chemotherapy treatment with dose reductions or with a longer interval between cycles than the women who did not develop infection: $22.0 \%$ of patients received reduced doses or had a prolonged interval of time between cycles $(p=0.355)$. Chemotherapy with paclitaxel/carboplatin was administered in $78.0 \%$ of the patients who developed infection compared with $80.6 \%$ of the patients without infection $(p=0.787)$. In both groups of patients, the median number of cycles of chemotherapy was 6 .

Table 3 provides the summary of characteristics of the adjuvant chemotherapy. Table 4 gives further details about the completeness of CRS, the median time to infection, and TTC.

The timing of postoperative chemotherapy, whether under, or over, 42 days, did not impact the probability of survival ( $p=0.715$ ). There were no significant differences in the survival curves when TTC was divided into intervals $(p=0.622)$. The presence of residual cancer did affect OS rates. Patients with no residual tumor had a higher probability of survival compared with patients with a residual tumor (Fig. $1 \mathrm{~A}, \mathrm{p}=0.001$ ). Next, we analyzed the impact of the infection on OS rates. Patients from the group without infections had a higher probability of survival compared with patients with infections (Fig. $1 B, p=0.038$ ). When we 
divided patients into two groups based on the completeness of their surgery, namely CCR0/CCR1 and CCR2/CCR3, we observed differences that were statistically significant in the first group. The patients with infections had poor survival outcomes (Fig. 1C, $p=0.011$ ); however, no such relation was demonstrated in the second group (Fig. 1D, $p=0.940$ ). Our analysis of the time elapsed to the start chemotherapy does not confirm that there is any impact of infection on OS. Furthermore, there were no statistically significant differences between the survival curves of pa- tients with and without infection in either the group with optimalTTC ( $<=42$ days) or the group with non-optimal TTC ( $>42$ days), $(p=0.657$ and $p=0.337$, respectively).

The survival outcomes in patients with multiple infections compared with patients with just one infection site, when comparing the survival probability of patients with wound infection with those with organ/space infections (e.g., peritonitis), showed no statistically significant differences ( $p=0.586$ and $p=0.527$, respectively). The expected 5 -year survival rate was $0.17(S D=0.07)$ for patients with

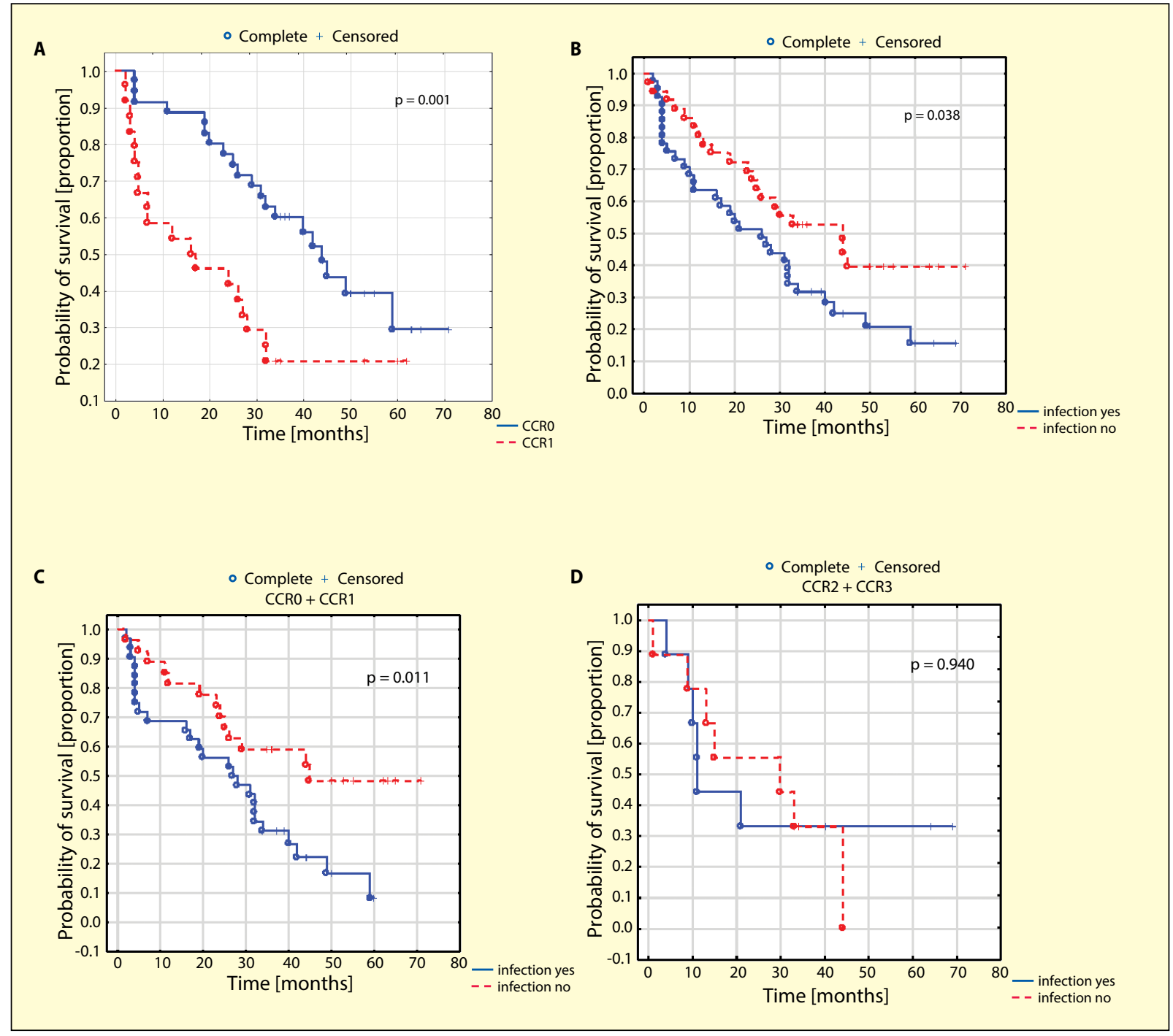

\section{Figure 1 Description}

Effect of residual disease on overall survival — statistically different survival curves in respect to CCR, among patients in whom CCR0 or CCR1 levels were achieved during surgery

B Effect of infection on overall survival - patients with infection have poorer survival outcomes compared with patients without infection

C Patients with infection have poorer survival outcomes compared with patients without infection

D No statistically significant differences in survival outcomes in relation to the occurrence or absence of infection

Figure $1 \mathrm{~A}$. Graph for OS of patients with respect to completeness of cytoreductive surgery; B. Graph for OS of patients with respect to infection; C. Graph for OS of patients with CCRO/CCR1 level in respect to infection; D. Graph for OS of patients with CCR2/CCR3 level in respect to infection 
infections and $0.40(S D=0.09)$ for those patients without infections.

\section{DISCUSSION}

In our study we found that infection was common following primary cytoreductive surgery with MPE, and that it significantly affected the median TTC in patients with advanced ovarian cancer by 10 days. The patients without infection were statistically more likely to receive chemotherapy within 25 days after surgery than during the 25-42day period compared with those patients who developed infection. However, overall, we found that the timing of postoperative chemotherapy did not impact the probability of survival compared with the development of infection, regardless of the TTC, which did cause a decrease in the survival curves.

To our knowledge, there are no studies evaluating the impact of perioperative infections on TTC, and associations between TTC for patients with and without infections, and the OS rate in women with advanced ovarian cancer (FIGO stage III and IV) following MPE.

Aggressive cytoreductive surgery is associated with surgical site infections, predominantly wound infections, but it is also associated with other site infections, such as urinary tract infections and bloodstream infections/sepsis $[20,28-29]$. It is unclear, however, whether the appearance of infection significantly affects TTC and, as a consequence, whether it has an impact on OS rates. The optimal time to chemotherapy after surgery in patients with ovarian cancer remains uncertain. It is known that extensive cytoreductive surgery and an overlapping infection (co-infection) can result in a longer recovery time and therefore delay the intended administration of chemotherapy. In our study, treatment delays were associated with postoperative infections. However, we did not find any correlation between a prolonged TTC and a decrease in the overall survival rate. Our finding is like that reported in a study conducted by Nagel et al., where the authors pointed out there was no association between $O S$ rates and changes in scheduled chemotherapy; also indicating the importance of personalized treatment plans [30]. The meta-analysis by Usón et al. [31] indicated that there was no correlation between the TTC after surgery and a higher risk of death, when assessing patients' 3-year survival rate following surgery with optimal TTC between 20 and 40 days. However, some authors have suggested that the time elapsed before the start of chemotherapy is crucial, when considered in relation to the completeness of the cytoreductive surgery. According to a meta-analysis conducted by Mahner et al. [32], early chemotherapy is critical for those patients who have no gross residual disease following surgery. For example, a delay of 7 days in the initiation of chemotherapy cor- related with a decreased OS rate. In contrast, the authors did not observe this correlation among patients who had residual cancer after cytoreduction. A similar dependence between early chemotherapy and a decreased OS rate has also been demonstrated by other authors. For instance, in the work of Tewari et al. [33] with a group of 1,718 patients who had a median TTC of 31 days, they found that $27.0 \%$ of the patients began chemotherapy $>40$ days after surgery. They also noted that the risk of death increased when the TTC among women with complete resection was $>25$ days. Moreover, both Seagle et al. [6] and Hofstetter et al. [7] found that the optimal time interval between surgery and chemotherapy was $21-35$ days. In contrast to the research findings cited here (above), the work of Hofstetter et al. [7] showed that prolonging TTC negatively influenced OS in patients with residual disease. Feng et al. [34] found that TTC was longer among those patients who underwent bowel resection: $72.0 \%$ of such patients began chemotherapy $>15$ days after surgery. However, their study did not confirm any association between the time to chemotherapy and OS rates. Moreover, when they divided patients into groups of those with, and without, residual diseases, they found no statistically significant differences. Nevertheless, the authors concluded that the TTC should be no longer than 6 weeks. Furthermore, both Wright et al. [8] and Aletti et al. [35] also reported that extended cytoreduction and postoperative complications were both associated with chemotherapy delay. In our study of an homogeneous group of patients with respect to bowel resection, namely patients after MPE, we found the median TTC to be 33 days. In patients with infection, compared with those without, the TTC differed by 9.5 days; however, the median TTC was still under 42 days. Matsuo et al. [28] observed that, among patients with perioperative infections (i.e., a positive microbiology result within 6 weeks of surgery), prolonged time to adjuvant chemotherapy ( $<60$ days compared with $\geq 60$ days) was associated with decreased survival outcomes as well as with decreased treatment responses. Poor survival rates were seen in patients with perioperative infections other than uncomplicated urinary tract infections. However, the authors did not observe such a dependence when they compared the OS rates of patients with multiple infections with those of patients who developed infections in only one site. In our work, we observed similar associations with respect to cases of multiple infections. It is worth emphasizing that our work has also confirmed the impact of perioperative infections on the long-term survival outcomes of patients with advanced ovarian cancer, but only after MPE.

As expected, the OS was also dependent on the tumor's residual status. Patients in our study with smaller residual tumors had better survival outcomes. Our observations also 
confirmed that the appearance of infection was associated with decreased survival outcomes among patients with no residual tumor or with a residual tumor of less than $2.5 \mathrm{~mm}$ (CCR0/CCR1). Interestingly, we did not record a correspondingly similar association in the cases of residual tumors of CCR2/CCR3. It seems that this latter fact may be related to complications that were associated with stoma formation; however, the retrospective nature of our research did does not allow for us to undertake a comparative analysis of infectious complications in ostomy and anastomosis.

One limitation of our study was that we did not analyze the etiological agents of infections and their susceptibility to antibiotics. For the purpose of our study, we decided that analysis of the results of infections treated without also making a thorough analysis of the etiological agents would be sufficient for our aims. The primary finding of our study was that infections are a common complication following MPE and have an impact on long-term survival outcomes. Consequently, we found that a comprehensive treatment of ovarian cancer ought to include infection management, as such can improve treatment results.

\section{CONCLUSIONS}

The absence of postoperative infection was associated with a better survival rate in patients. We noted that patients with infections experienced a longer time interval between surgery and the start of their chemotherapy without negatively impacting on their OS rates.

\section{Conflict of interests}

The authors declare that they have no conflicts of interest. The authors declare that they have not received any funding for this research study.

\section{REFERENCES}

1. Katsumata N, Yasuda M, Takahashi F, et al. Japanese Gynecologic Oncology Group. Dose-dense paclitaxel once a week in combination with carboplatin every 3 weeks for advanced ovarian cancer: a phase 3, open-label, randomised controlled trial. Lancet. 2009; 374(9698): 1331-1338, doi: 10.1016/S0140-6736(09)61157-0, indexed in Pubmed: 19767092.

2. Möbus V, Jackisch C, Lück HJ, et al. Cisplatin/paclitaxel vs carboplatin/paclitaxel: Optimizing of treatment in advanced ovarian cancer. European Journal of Cancer. 1997; 33: S119, doi: 10.1016/s09598049(97)85044-7.

3. Neijt JP, Engelholm SA, Tuxen MK, et al. Exploratory phase III study of paclitaxel and cisplatin versus paclitaxel and carboplatin in advanced ovarian cancer. J Clin Oncol. 2000; 18(17): 3084-3092, doi: 10.1200/JCO.2000.18.17.3084, indexed in Pubmed: 10963636.

4. Ozols RF, Bundy BN, Greer BE, et al. Gynecologic Oncology Group. Phase III trial of carboplatin and paclitaxel compared with cisplatin and paclitaxel in patients with optimally resected stage III ovarian cancer: a Gynecologic Oncology Group study. J Clin Oncol. 2003; 21(17):3194-3200, doi: 10.1200/JCO.2003.02.153, indexed in Pubmed: 12860964.

5. Oza AM, Cook AD, Pfisterer J, et al. ICON7 trial investigators. Standard chemotherapy with or without bevacizumab for women with newly diagnosed ovarian cancer (ICON7): overall survival results of a phase 3 randomised trial. Lancet Oncol. 2015; 16(8): 928-936, doi: 10.1016/S14702045(15)00086-8, indexed in Pubmed: 26115797.
6. Seagle BLL, Butler SK, Strohl AE, et al. Chemotherapy delay after primary debulking surgery for ovarian cancer. Gynecol Oncol. 2017; 144(2): $260-$ 265, doi: 10.1016/j.ygyno.2016.11.022, indexed in Pubmed: 27908531.

7. Hofstetter G, Concin N, Braicu l, et al. The time interval from surgery to start of chemotherapy significantly impacts prognosis in patients with advanced serous ovarian carcinoma - analysis of patient data in the prospective OVCAD study. Gynecol Oncol. 2013; 131(1): 15-20, doi: 10.1016/j.ygyno.2013.07.086, indexed in Pubmed: 23877013.

8. Wright JD, Herzog TJ, Neugut Al, et al. Effect of radical cytoreductive surgery on omission and delay of chemotherapy for advanced-stage ovarian cancer. Obstet Gynecol. 2012; 120(4): 871-881, doi: 10.1097/AOG.0b013e31826981 de, indexed in Pubmed: 22996105.

9. Alexander M, Blum R, Burbury K, et al.Timely initiation of chemotherapy: a systematic literature review of six priority cancers - results and recommendations for clinical practice. Intern Med J. 2017; 47(1): 16-34, doi: 10.1111/imj.13190, indexed in Pubmed: 27396268.

10. Liu Y, Yonemura Y, Levine EA, et al. BIG-RENAPE Group. Cytoreductive Surgery Plus Hyperthermic Intraperitoneal Chemotherapy for Peritoneal Metastases From a Small Bowel Adenocarcinoma: Multi-Institutional Experience. Ann Surg Oncol. 2018; 25(5): 1184-1192, doi: 10.1245/s10434018-6369-x, indexed in Pubmed: 29484565.

11. Esquivel J, Lowy AM, Markman M, et al. The American Society of Peritoneal Surface Malignancies (ASPSM) Multiinstitution Evaluation of the Peritoneal Surface Disease Severity Score (PSDSS) in 1,013 Patients with Colorectal Cancer with Peritoneal Carcinomatosis. Ann Surg Oncol. 2014; 21(13): 4195-4201, doi: 10.1245/s10434-014-3798-z, indexed in Pubmed: 24854493.

12. Jaffré $I$, Bordes $V$, Dejode $M$, et al. [The role of interval surgery in the treatment's strategy of advanced ovarian cancer]. Bull Cancer. 2011; 98(1): 37-42, doi: 10.1684/bdc.2010.1290, indexed in Pubmed: 21282089.

13. Chang SJ, Bristow RE. Evolution of surgical treatment paradigms for advanced-stage ovarian cancer: redefining ,optimal' residual disease. Gynecol Oncol. 2012; 125(2): 483-492, doi: 10.1016/j.ygyno.2012.02.024, indexed in Pubmed: 22366151.

14. Bois Adu, Reuss A, Pujade-Lauraine E, et al. Role of surgical outcome as prognostic factor in advanced epithelial ovarian cancer: A combined exploratory analysis of 3 prospectively randomized phase 3 multicenter trials. Cancer. 2009; 115(6): 1234-1244, doi: 10.1002/cncr.24149.

15. Eisenkop SM, Nalick RH, Teng NN. Modified posterior exenteration for ovarian cancer. Obstet Gynecol. 1991; 78(5 Pt 1): 879-885, indexed in Pubmed: 1923216.

16. Houvenaeghel G, Gutowski M, Buttarelli M, et al. Modified posterior pelvic exenteration for ovarian cancer. Int J Gynecol Cancer. 2009; 19(5): 968-973, doi: 10.1111/IGC.0b013e3181a7f38b, indexed in Pubmed: 19574794.

17. Benedetti Panici P, Di Donato V, Fischetti M, et al. Predictors of postoperative morbidity after cytoreduction for advanced ovarian cancer: Analysis and management of complications in upper abdominal surgery. Gynecol Oncol. 2015; 137(3): 406-411, doi: 10.1016/j.ygyno.2015.03.043, indexed in Pubmed: 25824857.

18. Alyami $M$, Lundberg $P$, Kepenekian $\mathrm{V}$, et al. BIG-RENAPE and RENAPE Working Groups. Cytoreductive Surgery and Hyperthermic Intraperitoneal Chemotherapy for Peritoneal Carcinomatosis in the Elderly: A Case-Controlled, Multicenter Study. Ann Surg Oncol. 2016; 23(Suppl 5): 737-745, doi: 10.1245/s10434-016-5519-2, indexed in Pubmed: 27600619.

19. Clark RM, Growdon WB, Wiechert A, et al. Patient, treatment and discharge factors associated with hospital readmission within 30 days after surgical cytoreduction for epithelial ovarian carcinoma. Gynecol Oncol. 2013; 130(3): 407-410, doi: 10.1016/j.ygyno.2013.05.034, indexed in Pubmed: 23747329.

20. Capone A, Valle M, Proietti F, et al. Postoperative infections in cytoreductive surgery with hyperthermic intraperitoneal intraoperative chemotherapy for peritoneal carcinomatosis. J Surg Oncol. 2007; 96(6): 507-513, doi: 10.1002/jso.20837, indexed in Pubmed: 17708508.

21. Chi DS, Zivanovic O, Levinson $\mathrm{KL}$, et al. The incidence of major complications after the performance of extensive upper abdominal surgical procedures during primary cytoreduction of advanced ovarian, tubal, and peritoneal carcinomas. Gynecol Oncol. 2010; 119(1): 38-42, doi: 10.1016/j.ygyno.2010.05.031, indexed in Pubmed: 20609464.

22. Szymankiewicz M, Koper K, Dziobek K, et al. Microbiological monitoring in patients with advanced ovarian cancer before and after cytoreductive surgery - a preliminary report. Current Issues in Pharmacy and Medical Sciences. 2017; 30(4): 198-202, doi: 10.1515/cipms-2017-0038. 
23. Singh S, Guetzko M, Resnick K. Preoperative predictors of delay in initiation of adjuvant chemotherapy in patients undergoing primary debulking surgery for ovarian cancer. Gynecol Oncol. 2016; 143(2): 241-245, doi: 10.1016/j.ygyno.2016.09.004, indexed in Pubmed: 27615398.

24. Joseph N, Clark RM, Dizon DS, et al. Delay in chemotherapy administration impacts survival in elderly patients with epithelial ovarian cancer. Gynecol Oncol. 2015; 137(3): 401-405, doi: 10.1016/j.ygyno.2015.03.052, indexed in Pubmed: 25839911.

25. Minar L, Felsinger M, Rovny I, et al. Modified posterior pelvic exenteration for advanced ovarian malignancies: a single-institution study of 35 cases. Acta Obstet Gynecol Scand. 2017; 96(9): 1136-1143, doi: 10.1111/aogs.13177, indexed in Pubmed: 28585317.

26. Sugarbaker PH. Technical handbook for the integration of cytoreductive surgery and perioperative intraperitoneal chemotherapy into the surgical management of gastrointestinal and gynecologic malignancy. 4th ed. Grand Rapids. The Ludann Company. ; 2005

27. Matsuo K, Lin YG, Roman LD, et al. Overcoming platinum resistance in ovarian carcinoma. Expert Opin Investig Drugs. 2010; 19(11): 1339-1354, doi: 10.1517/13543784.2010.515585, indexed in Pubmed: 20815774.

28. Matsuo K, Prather CP, Ahn EH, et al. Significance of perioperative infection in survival of patients with ovarian cancer. Int J Gynecol Cancer. 2012; 22(2): 245-253, doi: 10.1097/IGC.0b013e31823bd6db, indexed in Pubmed: 22228425.

29. Tran CW, McGree ME, Weaver AL, et al. Surgical site infection after primary surgery for epithelial ovarian cancer: predictors and impact on survival. Gynecol Oncol. 2015; 136(2): 278-284, doi: 10.1016/j.ygyno.2014.12.007, indexed in Pubmed: 25499962.
30. Nagel Cl, Backes FJ, Hade EM, et al. Effect of chemotherapy delays and dose reductions on progression free and overall survival in the treatment of epithelial ovarian cancer. Gynecol Oncol. 2012; 124(2): 221-224, doi: 10.1016/j.ygyno.2011.10.003, indexed in Pubmed: 22055764.

31. Usón PL, Bugano DD, França MS, et al. Does Time-to-Chemotherapy Impact the Outcomes of Resected Ovarian Cancer? Meta-analysis of Randomized and Observational Data. Int J Gynecol Cancer. 2017; 27(2): 274-280, doi: 10.1097/IGC.0000000000000923, indexed in Pubmed: 28114235.

32. Mahner S, Eulenburg C, Staehle A, et al. Prognostic impact of the time interval between surgery and chemotherapy in advanced ovarian cancer: analysis of prospective randomised phase III trials. Eur J Cancer. 2013; 49(1): 142-149, doi: 10.1016/j.ejca.2012.07.023, indexed in Pubmed: 22921185.

33. Tewari KS, Java JJ, Eskander RN, et al. Early initiation of chemotherapy following complete resection of advanced ovarian cancer associated with improved survival: NRG Oncology/Gynecologic Oncology Group study. Ann Oncol. 2016; 27(1): 114-121, doi: 10.1093/annonc/mdv500, indexed in Pubmed: 26487588.

34. Feng $\mathrm{Z}$, Wen $\mathrm{H}, \mathrm{Bi}$, et al. Prognostic impact of the time interval from primary surgery to intravenous chemotherapy in high grade serous ovarian cancer. Gynecol Oncol. 2016; 141(3): 466-470, doi: 10.1016/j. ygyno.2016.04.016, indexed in Pubmed: 27098361.

35. Aletti GD, Long HJ, Podratz KC, et al. Is time to chemotherapy a determinant of prognosis in advanced-stage ovarian cancer? Gynecol Oncol. 2007; 104(1): 212-216, doi: 10.1016/j.ygyno.2006.07.045, indexed in Pubmed: 17023033 . 